\title{
Indoor air pollution and the contribution of biosensors
}

\author{
Evgeni Eltzov ${ }^{1,2}$, Abri Lavena De Cesarea ${ }^{3}$, 'Yuen Kei Adarina Low ${ }^{4}$ and Robert S. Marks²,45*
}

\begin{abstract}
A vast majority of people today spend more time indoors than outdoors. However, the air quality indoors may be as bad as or even worse than the air quality outside. This is due to the continuous circulation of the same air without proper ventilation and filtration systems, causing a buildup of pollutants. As such, indoor air quality monitoring should be considered more seriously. Indoor air quality (IAQ) is a measure of the air quality within and around buildings and relates to the health and comfort of building occupants. To determine the IAQ, computer modeling is done to simulate the air flow and human exposure to the pollutant. Currently, very few instruments are available to measure the indoor air pollution index. In this paper, we will review the list of techniques available for measuring IAQ, but our emphasis will be on indoor air toxicity monitoring.
\end{abstract}

Keywords: Biosensors, Indoor pollution, health, sick building syndrome

'Department of Postharvest Science of Fresh Fruit, The Volcani Center, Agricultural Research Organization, Bet Dagan 50250, Israel

${ }^{2}$ School of Material Science and Engineering, Nanyang Technology University, Nanyang Avenue, 639798, Singapore

${ }^{3}$ Biosensorix, Raffles Place, 048616 Singapore

${ }^{4}$ Department of Biotechnology Engineering, Faculty of Engineering Sciences, Ben Gurion University of the Negev, Beer-Sheva 84105, Israel;

${ }^{5}$ The Ilse Katz Centre for Meso and Nanoscale Science and Technology, BenGurion University of the Negev, Beer-Sheva 84105 , Israel

*Corresponding author: R. S. Marks E-mail: rsmarks@bgu.ac.il

DOI: 10.2478/ebtj-2019-0003

(C) 2019 Authors. This work was licensed under the Creative Commons AttributionNonCommercial-NoDerivs 4.0 License.

\section{Introduction}

Air pollution is an emerging problem today, and various health issues have been linked to poor air quality. Air, the very substance essential for our existence, is also responsible for the premature deaths of more than two million people worldwide when it is contaminated with deleterious chemicals. Respiratory infection, heart disease, and lung cancer are the most common causes of premature deaths resulting from air pollution. One obvious solution is to stay indoors when the air quality is in the unhealthy range. However, little attention and emphasis has been placed on air pollution within office buildings and homes.

The indoor environment has always been considered free from health-damaging pollutants, and Americans spend approximately 22 hours everyday indoors. However, indoor air quality (IAQ) may be far from perfect. The quality of indoor air is influenced by ventilation systems (air conditioning, humidifier system), hygiene (carpets maintenance), office equipment and furnishings, surface coatings, levels of microbial flora, (mould, bacteria) and endotoxins. Poor IAQ leads to headache, fatigue, eye and nose irritation, and sick building syndrome (SBS): a term coined to describe situations in which building occupants experience acute health and comfort issues linked to the amount of time they spend in a building, with no specific illness or causes identified. Office workers in a poor IAQ building have lower productivity, nasal engagement, allergy, and higher asthma occurrence, therefore resulting in negative economic impact. Many independent experiments have shown a direct correlation between pollution rate and work productivity, with improved air quality positively increasing work productivity $(2,3)$. Studies have also shown that long-term exposure to low levels of pollutants places individuals at higher risk of adverse health effects, and certain pollutants (e.g., asbestos) are cancer-causing.

Due to the increased awareness of IAQ in recent years, many organizations have conducted studies and set guidelines to ensure a safe working environment. The US Occupational Safety and Health Administration (OSHA), US National Institute for Occupational Safety and Health (NIOSH), American Congress of Governmental Industrial Hygienists 
(AC-GIH) and the World Health Organization (WHO) are some bigger organizations that have accepted that poor IAQ poses a risk to human lives, and have taken steps to roll out guidelines and enforce laws to ensure a more secure indoor environment.

Human activities such as cooking and the use of cleaning chemicals can also introduce harmful particulate matter and volatile organic compounds (VOCs). In high humidity regions, mold breeds bountifully and releases spores, which causes allergic reactions or poisoning by mycotoxins when in high quantities. Many other combinations of chemical, microbiological, and physical pollutants also lead to poor IAQ. Although the right ventilation and building care can improve IAQ, real-time monitoring of the quality of indoor air can largely improve the efficiency and cost for maintenance of good IAQ. Conventional methods (gas chromatography, fluorometry and liquid chromatography (HPLC)) allows the precise and sensitive detection of pollutants, but usually only one compound or a group of compounds similar in structure can be identified at once. These techniques require the sample to be inserted in a liquid matrix. They are time-consuming, expensive and require well-skilled personnel. Smart gas sensing systems i.e, (electronic noses), quartz-crystal resonators, and other sensing methods seem to meet the criteria for indoor air monitoring. However, the drawback of all these applications is that they are unable to measure the biological impacts of the air pollutants tested for the different types of toxicities (e.g., cyto/neuro/geno toxicities or endocrine disrupting effects). In this sense, biosensors which are composed of whole-cell systems seem to be a desirable choice. The definition of a biosensor is a self-contained bionic integrated device containing a biological recognition element (enzyme, antibody, receptors, and microorganisms), that can respond in a concentration-dependent manner to a biochemical species. Biosensors offer promising advantages for air toxicity analysis due to its low cost, ease-of-use and real-time monitoring capability with minimal sample preparation.

This review paper will first discuss the source and health effects of the different subcategories of pollutants before highlighting the techniques (conventional and biosensors) used to monitor IAQ. The emphasis here is on biosensors for indoor air toxicity monitoring.

\section{Indoor air pollutants - sources and health effects}

Indoor air pollution is a global health problem and millions are at risk of chronic respiratory diseases. However, the lack of knowledge and information about its environmental impacts on health has caused an uncontrolled production and emission of pollutants indoors. In developed countries, a majority of people spend up to $90 \%$ of their time indoors (home and offices) (4) and inhale an average of $22 \mathrm{~m} 3$ air per day. With substantially higher levels of indoor as compared to outdoor VOC species, (5) it is important to trace the source of pollutants, the negative health effects brought about by pollutants and identify ways to monitor the IAQ.

WHO has defined health as a state of complete physical, men- tal and social well-being. Different parameters (e.g., changes in well-being and harmful effects) should therefore be taken to determine indoor health. Health effects may be divided into five groups - immune or hypersensitivity; respiratory; cellular; neurogenic and sensory; and cardiovascular. Evaluation of environmental health effects include identification of the health problem and determining the source of the pollutant. In low concentrations of pollutants (lower than existing guidelines), health issues are believed to be generally reversible and unspecific.

Properties of materials, its colors, and style are usually the main considerations when furnishing an interior. Fiber-glass boards are typically chosen to construct office cubicles due to its sound deadening properties, and certain fabrics, adhesives, finishes/coatings are used due to its affordability. However, some materials continuously emit harmful vapors over time, and the ventilation systems may not effectively remove or dilute these emissions. Personal computers are another source of pollution. After being in service for 500 hours (3 months of office use), PCs were found to emit phenol, toluene, 2-ethylhexanol, formaldehyde, and styrene (6). Even though most pollutants are found in minute concentrations that are much lower than proposed existing guidelines, constant exposure to multicomponent sources of pollutants may affect individuals differently and not in a way that is expected from an individual pollutant. In these cases, it is impossible to assess the interactions between compounds in a mixed exposure because the interaction mechanisms are too complex for normal toxicological evaluation. Workers exposed to such air quality have reported sick building symptoms. In industrial countries, office workers make up more than half of the entire workforce, and thus there is an urgent need to understand the health effects caused by poor indoor air quality. We will describe the sources and health impacts of some of the most common pollutants below.

Carbon dioxide $\left(\mathrm{CO}_{2}\right)$ is formed in the body and humans continuously exhale this by-product of metabolism. As such, the generation of $\mathrm{CO}_{2}$ typically varies according to the office occupant load. During office hours, $\mathrm{CO}_{2}$ concentration remains almost stable but dips during lunch time. Ventilation ensures an effective exchange of air content within a building. However, if the outdoor air quality is poor, overventilation may increase the concentration of pollutants indoors. It has been reported that in some Hong Kong air-conditioned offices that overventilation had created a situation of low $\mathrm{CO}_{2}$ concentration indoors, but with the drawback of high outdoor pollutants (ozone, nitrogen dioxide) (7). Therefore, considering the pollution of outdoor air is important to optimize the efficiency of ventilation. A system to filter out pollutants from the intake of outside air would be sensible. High $\mathrm{CO}_{2}$ concentration causes occupants to feel drowsy, get headache, and lower their activity levels, but these symptoms are reversible when the total indoor $\mathrm{CO}_{2}$ is reduced to neutral and below 1000 ppm levels (8).

Volatile organic compounds (VOC) are a class of organic compounds with boiling points from $50-100^{\circ} \mathrm{C}$, up to 240 $260^{\circ} \mathrm{C}$ and was suggested as the potential sources for SBS. Likewise, for $\mathrm{CO}_{2}$, the main source of VOCs in a building 
comes from human activities and ineffective ventilation rate. The primary emission of VOCs (e.g., solvents) is produced in new or renovated offices, and homes up to several months old. Office equipment and different physical (e.g., heat, weariness, and UV-light) and chemical (e.g., maintenance, moisture) processes of the building materials are the secondary sources of VOC emission that continuously contributes to indoor pollution. Mucosal irritation and nonspecific symptoms such as headache are associated with VOCs present in the air. When healthy occupants were exposed to VOCs, they reported eye, nose, and throat irritation and reduced air quality ratings relative to clean air conditions. However, occupants who have complained about poor IAQ have milder symptoms. This mismatch in the report may be due to the possible VOCs and $\mathrm{O}_{3}$ reactions. When formed, secondary products including ultrafine particles may add to possible damaging effects. One of the most harmful and injurious VOC is formaldehyde ( $\mathrm{HCHO}$ ), which is used as adhesive in pressed wood products, building materials, a preservative in paints, coatings, and as a finish to coat paper products $(9,10)$. Many governing agencies have established limits to the long-term exposure to HCHO: 0.07 ppm by WHO (11); 1 ppm by NIOSH (12); 0.06 ppm (1 hour average) by the Chinese Environmental Protection Agency (EPA) and $80 \mathrm{ppb}$ by the Ministry of Health and Welfare in Japan, but these values are lower than the detection limit of the human sense of smell (410 ppb) (13). HCHO is very soluble in water and irritates the upper respiratory tract and mucous membranes of the eyes when present at $0.1 \mathrm{ppm}$ onwards, but the irritation is more pronounced at or above $1 \mathrm{ppm}$. It is also carcinogenic and a chemical mediator of apoptosis. Therefore, detection of $\mathrm{HCHO}$ is important as it helps to reduce the risk of negative health effects.

Indoor combustion processes (e.g., gas application, smoking, and woodstoves) contribute to indoor nitrogen oxides $\left(\mathrm{NO}_{\mathrm{x}}\right)$ pollution, but the main source is outdoor-to-indoor transmission. In the day, indoor concentrations of nitric oxide (NO) ranges from several hundred ppb to less than $1 \mathrm{ppb}$, while nitrogen dioxide $\left(\mathrm{NO}_{2}\right)$ levels is usually from $20-50 \mathrm{ppb}$, and rarely goes below $10 \mathrm{ppb}(14) . \mathrm{NO}_{\mathrm{x}}$ reacts rapidly with $\mathrm{O}_{3}$ or $\mathrm{O}_{2}$ to form $\mathrm{NO}_{2}$, which is the main pollutant in an indoor environment. This chemical reaction is reversible in the presence of sunlight, where photolysis of $\mathrm{NO}_{2}$ regenerates $\mathrm{NO}$ and $\mathrm{O}_{3}$. Chronic exposure to low levels of indoor $\mathrm{NO}_{2}$ is not well understood, but reports have shown that the $\mathrm{NO}_{2}$ may damage certain lung cells, oxidize proteins with free radicals, and reduce resistance to infection by altering macrophage and immune function (15). Exposure studies have also indicated that the major target site for the action of $\mathrm{NO}_{2}$ is the terminal bronchioles. Most epidemiological studies on the health effects of $\mathrm{NO}_{2}$ focuses on morbidity rather than mortality (16).

As discussed above, newly built or renovated buildings contain pollutants coming from the materials used for construction and furnishing. When buildings start to age, complex microbial communities (including bacteria and fungi) also begin to inhabit them. Occupants of moisture-prone buildings are often exposed to multiple, different acting toxins of microbial origin and pathogens (17-20). Other sources of bacterial contamination include dust, carpets and air conditioning (cooling coils, filters, ducts, humidifiers, drip pans, air-cooling units) (21-24). The most frequent diseases related to biological factors are legionnaire's disease, allergic reactions, hypersensitivity pneumonitis, humidifier fever and tuberculosis (25). In addition to toxin pollution, more than 200 VOCs (e.g., alcohols, aldehydes, ketones, terpenes, esters, amines, and aromatic compounds, sulfur-containing, and nitrogen-containing compounds) have been associated with different fungi (26). Molds are also common in aged buildings and affect the health of occupants. About $5 \%$ of individuals have some allergic airways symptoms from molds during their lifetime (25). The spores from molds can induce infection and toxic or irritant effects such as nasal and sinus irritation or congestion, dry hacking cough, wheezing, skin rashes or burning and watery reddened eyes (27). Persons prone to asthma may also have attacks triggered by mold, on top of infections of the skin and nails, body aches, and headache or memory problems. Airborne bacteria or fungal species are also common contaminants found in indoor environments (28). Usually, air-conditioning systems or open windows are the main source of such microorganisms, which are spread thoughout the rooms via dust or water droplets (29).

Besides mold, other sources of allergens are dust mites and insects. They enter buildings by ventilation systems or ajar and open windows. The type and concentration of allergens varies with season, weather condition, geographical situation, and the local indoor environment. While the immune system of humans can recognize and react to foreign macromolecular particles as well as cellular pathogens, some allergens may trigger adverse effects. Among them, allergic asthma and extrinsic allergic alveolitis are the two most serious allergic reactions caused by allergens in the indoor air. Contaminated humidifiers in non-industrial buildings have been correlated with allergic asthma and humidifier fever. The contaminated humidifier generates aerosols containing many microorganisms and their debris, together with a wide range of other microorganisms, including thermophilic actinomycetes, molds, bacteria and nematodes (30).

Tobacco smoke is an indoor pollutant caused by humans. Smoke can be classified as side stream (direct exhalation from the smoker) or mainstream smoke (emissions between puffs), (31) and contributes to the main source of fine particulate pollution indoor in developed countries albeit at a reducing rate in some countries thanks to drastic regulations. Besides particulates, aerosol contains several thousands of substances in a mixture of particles, vapors, and gases. It has been shown that with closed windows and doors, the concentration of indoor air pollutants measured at a different time after smoking were obviously higher than pre-smoking, and $\mathrm{HCHO}$ and VOCs still exceed the standard limit after 3 hours. Therefore, ventilation plays an important role in regulating the indoor air content. Smoking also has health impacts on non-smokers $-43.5 \%$ of 


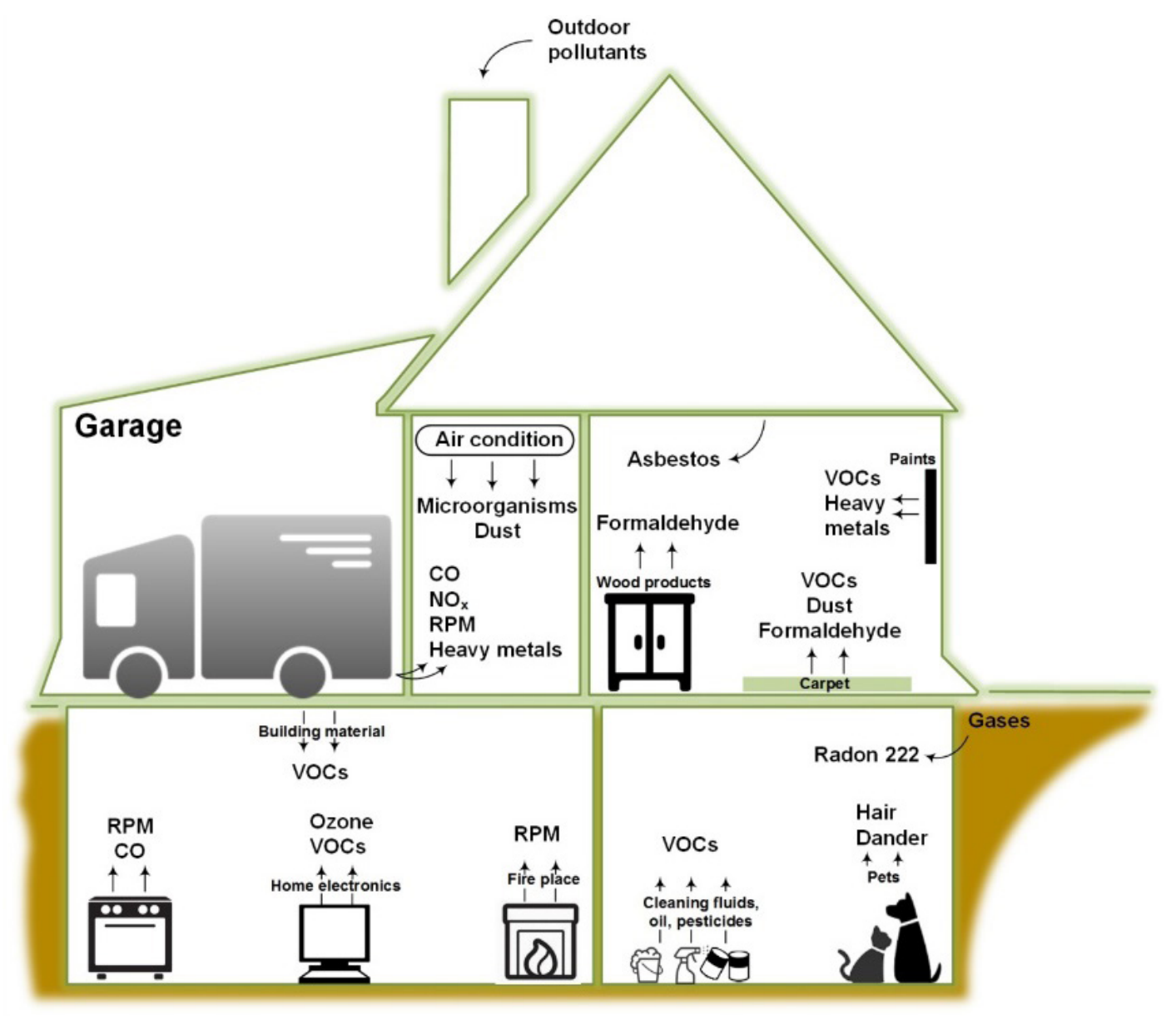

Figure 1. Sources of indoor air pollutants.

non-smoking employees recalled some discomfort from the smoke at work. Second-hand smoke can induce asthma and exacerbation in children and adults (32). Toxins from the inhalation of mainstream smoke are also typically more dangerous than from direct smoking due to a 20 - 100 times higher exposure to $\mathrm{N}$ - nitrosodimethylamine, a potent carcinogen for passive smokers (33). To put things into perspective, an individual standing $50 \mathrm{~cm}$ away from a cigarette would have inhaled more than 10 times the amount of carbonyl compounds than that inhaled directly by a smoker(34). Several epidemiological studies in the US, Canada, and France have showed a higher risk of cancer from radon for smokers than for never-smokers (35). Radon is responsible for lung cancer among non-smokers and there are about 21,000 lung cancer deaths each year (32).

Studies have also shown that radon may be present within the soil surrounding a building. This inert radioactive gas arises directly from the decay of radium-226 contained in various minerals (36). Thus, the structural defects in floors and walls, drains and piping, electrical connections and cellars with earth floors may be the main sources of radon within a building (37). The half-life of radon decay is 3.82 days, which creates a series of short-lived radioisotopes known as progeny or radon daughters(e.g., electrically charged Po-218 and Po-214) (38). Building occupants are at risk of exposure to progeny, which can attach to airborne particles and be inhaled into the body.
The concentration of indoor particles is a cause for concern for building occupants. Movement of people aids with the exchange of air into and out of the building, which introduces particles with variable size distribution. Studies have shown that $60-75 \%$ of outdoor particulate matter $\leq 2.5 \mu \mathrm{m}\left(\mathrm{PM}_{2.5}\right)$ and $65 \%$ of outdoor particulate matter $\leq 10 \mu \mathrm{m}\left(\mathrm{PM}_{10}\right)$ in aerodynamic diameter effectively penetrates indoors. These particulate matter include dust, dirt, soot, smoke and liquid droplets. High concentrations of $\mathrm{PM}_{2.5}$ has been associated with increased mortality $(39,40)$, as the fine particles can get deep into the lungs and even into the bloodstream. Heavy metals on these fine particles may interfere with specific enzyme systems and blood production in humans, causing brain (41) and kidney damage (42).

The use of brominated flame retardant (BRF) (e.g., polybrominated diphenyl ethers (PBSEs)) in many commercial products including building materials, electronic equipment, lighting, electric wiring, textiles, furniture, and industrial paint has attracted enormous attention over the last decade (43). While the use of BRF reduces the risk of fire, it has brought about another set of problems. Degradation of BRF emits vapors that have negative health impacts. Studies have shown that BFR has endocrine disrupting effects (44), neurotoxic effects (45), and causes tissue accumulation (46). However, limited toxicity information is present, and results are mostly incomplete and often conflicting. 
There are many other pollutants that can be found present in minute amounts in indoor air environments, such as pesticides that were dispersed in the fields and have infiltrated nearby habitats (47). Radicals from office equipment and microwave, the reaction of ozone with different pollutants that create toxic compounds, the use of phthalate esters as softeners in the production of polymeric materials, and natural occurring parameters such as temperature, relative humidity and amount of light have an effect on the concentration of indoor pollutants. Certain pollutants (chemicals, aldehydes, and terpenes) can exude strong odors. Thus, it is logical to perceive odors in the indoor chemical composition. However, the sources of indoor pollutants are usually non-specific and mostly mixed in the composition, causing difficulty in characterizing and identification.

Toxicity evaluation of different indoor pollutants on humans may thus be determined by a procedure of specific human biomarkers, which could be associated with the occurrence of SBS. For example, some studies show that reactive oxygen species (ROS) cause oxidative damage to DNA and may serve as a predictor of SBS. As a result of DNA damage, 8-hydroxydeoguanosine (8-OHdG) may be excised with hydroxylation by constitutive enzymatic repair systems, excreted in the urine and used as an SBS biomarker. Fig. 1 shows the source of various indoor air pollutants.

In the next section, we will describe some conventional methodologies and biosensor techniques are used to determine the IAQ, including the use of genotoxicant bioreporters.

\section{Conventional and biosensor techniques for indoor pollutant detection}

In the previous section, we have identified a list of indoor pollutants that can negatively affect human health and requires monitoring. Various biological, physical and chemical sensors are continuously being developed for this purpose. Four key parameters are usually used to evaluate a sensor's performance: sensor sensitivity, the probability of correct detection, false positive rate and response time (48). The main challenge in monitoring and measuring indoor pollutants is that contaminants move irregularly in a building and are quite diffused and in small density. Factors such as heating, ventilation, air-conditioning system, building layout, partitions, furniture, properties of a contaminant source, and its location, will affect the dispersion and/or deposition inside a building (49).

Traditional analytical techniques for air pollutant monitoring like active and passive sampling and diffusive samplers are used for monitoring chemical pollutants (50). For $\mathrm{NO}_{2}$ sampling, samples collected are sealed in protective containers and stored in a freezer till analysis with UV-Vis Spectrophotometers in accordance with ISO 16000-15. Formaldehyde monitoring follows ISO 16000-4 and ISO 16000-2 and is analyzed by high-performance liquid chromatography (HPLC) equipped with ultraviolet (UV) detector. $\mathrm{CO}_{2}$ is monitored by a data logging system, and these complex devices cost between $\$ 160$ and $\$ 600$ each. To evaluate the presence of dampness and molds, trained inspectors were employed for visual evaluation using a standardized checklist. Data from the checklist are then entered into a computer database, and data management is conducted with a standardized procedure including quality assurance and quality control (50). In spite of the high accuracy of the abovementioned traditional analytical methods, the time-consuming issue of sampling and testing, requirement for expensive laboratory equipment and skilled personnel has made these techniques unattractive as compared to the use of biosensors.

Theoretically, traditional analytical methods are the gold standard for pollutant detection. However, within each step of the analytical process (e.g., sampling, desorption, separation, and detection), problems may arise. Highly reactive compounds (e.g., free radicals) are difficult to collect, and analytes may not be able to get trapped or may decompose on the sorbent (51). Polar compounds and molecules with high molecular weight are difficult to be desorbed from the sorbent. The reaction of reactive molecules with other materials or decomposition may complicate or prevent the separation step (52). During detection, characteristic ions of certain compounds may be overlooked when the analyte is scanned with a mass spectrometer at scan ranges that are too high. Mass spectrometer and flame ionization detectors respond less to oxidized compounds than to aromatic or aliphatic hydrocarbon (52). Also, many compounds are still not included in the libraries commonly used to record and match airborne pollutants, and thus cannot be identified accurately. All these factors will affect the reliability of conventional techniques.

Sensors, on the other hand, require minimal manpower and post-experimental data processing. A typical sensor is built to produce a signal or a change to the chemical or physical properties in the presence of the tested analyte. The change is collected, amplified and converted into measurable values via a transducer. Fig. 2 describes the path of the sensing mechanism, from the detection of an analyte in the air to the representation of the measurable value on the computer. A single sampling location cannot be the representation for the space measured, and usually more than one sampling location will be required to increase measurement accuracy (53). Therefore, a network of sensors will be necessary to provide efficient and effective information on the indoor air pollutant content. In addition to identification, specific concentrations is the most important and valued data for air pollution control.

Physical sensors measure the temperature, relative humidity, air movement and ventilation indoors while chemical sensors contain a recognition element that is sensitive to stimuli produced by different chemical compounds (54). Generally, chemical sensors are widely classified into gas, liquid and solid sensors, and further categorized as optical, electrochemical, thermometric and gravimetric sensors according to the operating principle of the transducer. The concept and design of an electronic nose (e-nose) was first reported by Persaud and Dodd (55) in 1982 as an example of a chemical sensor that consists of a range of independently semi-selective and reversible gas sensors combined with pattern recognition software, mimicking the human olfactory system. This technique is cheap and 


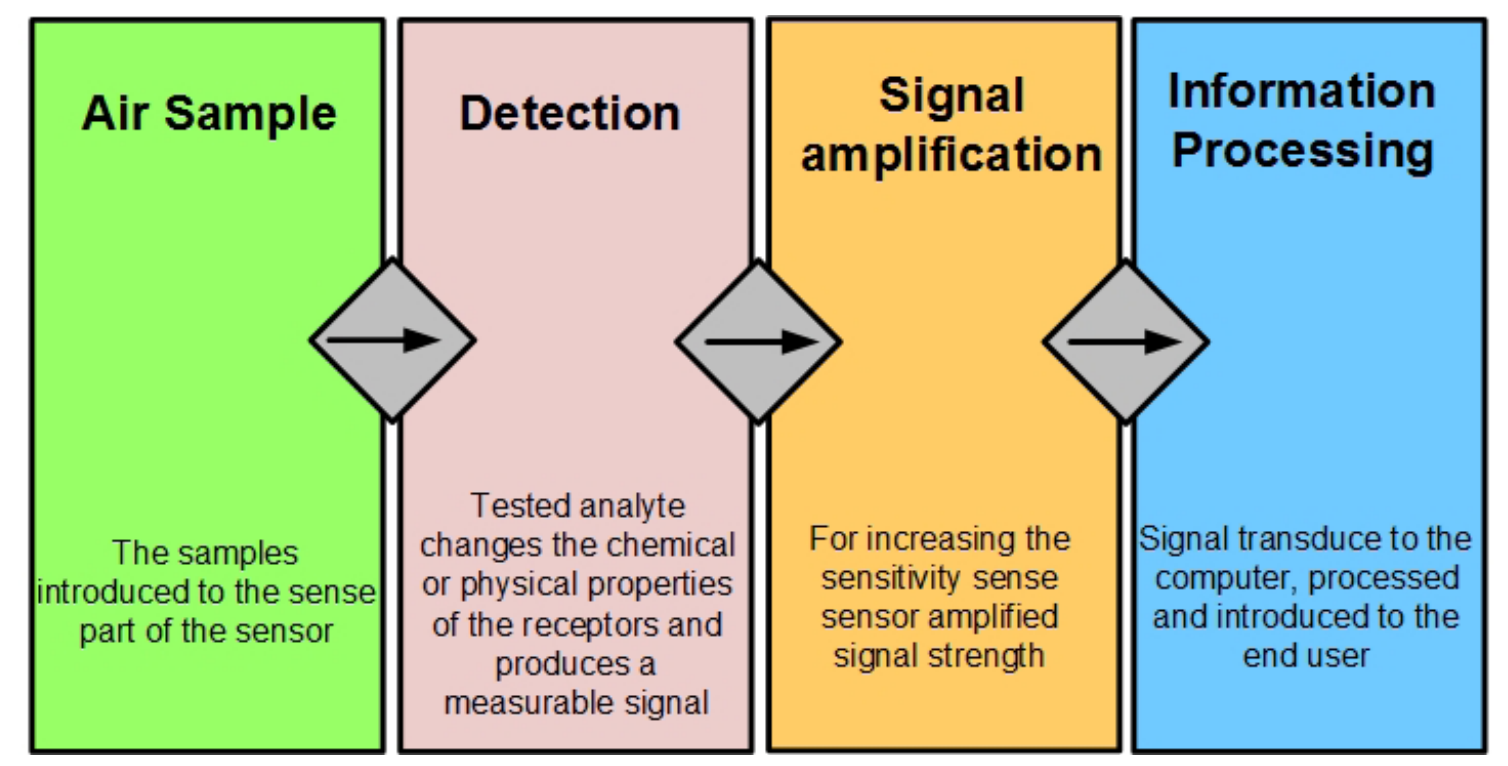

Figure 2. Green box: "Samples introduced to the sensing part of the sensor"; Pink box: "Tested analyte changes the chemical or physical properties of the sensing part and produces a measurable signal"; Orange box: "For increasing the sensitivity of the sensor and amplifying signal strength"; Blue box: "Signal transduced to the computer, processed and introduced to the end user".

easy to operate, thus suitable for use as a general purpose detector of vapor chemical and can be used for online or real-time measurement (56). A major challenge and concern for the use of e-nose is the long-term stability of the sensing system, which may be influenced by the ever-changing physical factors (temperature, pressure, and humidity), leading to unacceptable selectivity and degrading sensitivity levels. Therefore, short-term online measurement of VOCs in indoor air was developed (57). Targeted VOCs (formaldehyde, benzene, toluene, and BTEXs) have shown good performance in qualitative and semi-quantitative measurements. Another e-nose application is a miniaturized, low-cost device based on metal-oxide sensors and signal processing techniques (58). This device targets the quantification of $\mathrm{CO}$ and $\mathrm{NO}_{2}$ in mixtures with relative humidity of volatile organic compounds measured by using an optimized gas sensor array and highly effective pattern recognition technique. Testing of this device in real operation showed its capability to identify and discriminate concentrations as low as $5 \mathrm{ppm}$ for $\mathrm{CO}$ and $20 \mathrm{ppb}$ for $\mathrm{NO}_{2}$, enabling it to reach the necessary sensitivity towards target pollutants and selectivity towards the typical interfering gas species. During the last decade, developments in nanotechnology created a huge potential for the development of cost-effective, highly sensitive and portable devices for air toxicity monitoring. Nanomaterial characteristics (e.g., high surface-to-volume ratio and hollow structure) provide ideal conditions for gas molecule adsorption and storage (59). Therefore, gas sensors based on different nanomaterials (e.g., graphene $(60,61)$, metal-oxides (62-64), single-walled carbon tubes $(\mathrm{CNT})(65,66)$ and multiwall carbon tubes (MWCNT) $(67,68)$ nanotubes have been widely investigated. For example, a hybrid CNT and tin oxide $\left(\mathrm{CNT} / \mathrm{SnO}_{2}\right)$ has been used to detect $\mathrm{NO}_{2}$ gas (69) and $\mathrm{HCHO}$ (70); while the hybrid CNT and tungsten dioxide $\left(\mathrm{CNT} / \mathrm{WO}_{3}\right)$ have detected $\mathrm{CO}$ and $\mathrm{NO}_{2}$ gas (71). Chemically modified multi-walled CNTs and PMMA composite were used to detect methanol and $\mathrm{NH} 3$ gases (72), while $\mathrm{SnO}_{2}$ coated onto MWCNTs have detected $\mathrm{C}_{4} \mathrm{H}_{10}, \mathrm{CH}_{4}$, $\mathrm{CO}$ and LPG gases (73). Platinum and palladium-nanoclusters functionalized CNTs detected $\mathrm{NO}_{2}, \mathrm{H}_{2} \mathrm{~S}, \mathrm{NH}_{3}, \mathrm{CO}$ up to a low limit of sub-ppm levels (74).

A piezoelectric microcantilever in resonating mode, which shifts its resonance frequency due to mass loading, has shown high sensitivity for chemicals and has potential application related to artificial noses (75). For example, piezoelectric substrate modified with $\mathrm{SnO} 2$ thin films was used for development hydrogen gas surface acoustic wave (SAW) sensors (76). In this study, enhancement of the sensor performance was proceed by creating bi-layer sensing film made from $\mathrm{SnO} 2$ and highly dispersed palladium nanoparticle layers. Also, SAW based sensors were used to monitor methanol, diesels and benzenes (77), nitrogen dioxides (78), organic volatiles (79), methane (80), particles (81) in the air. Another piezoelectric microcantilever coated with zeolite has been used for the detection of Freon gas (82). The linear relationship between the frequency shift in percent and the concentration of the Freon gas was determined, where the sensitivity of the sensor was standing at $-0.0024 \%$ / ppm. Quartz crystal microbalance (QCM) approaches have been widely used for air toxicity monitoring. This approach is based on the electromechanical oscillation changes of the metal electrode modified quartz crystals. Specificity of this approach is based on chemical sensitive material deposited on a QCM surface, after which exposure with the analyte produced oscillation frequency changes proportional to the adsorbed mass. For example, organic polymer pentacene integrated on the QCM surface allowed monitoring for the presence of VOCs (e.g., benzene, toluene or xylenes) in air. Furthermore, this sensing layer was also active in the presence of $40 \%$ relative 
humidity, thus showing that the sensor allows operation at wet environments (83). Another QCM based research has shown strong affinity of the tetra-tert-butyl copper phthalocyanine towards toluene (84). Nevertheless, with higher reproducibility and sensitivity (10 $\mathrm{ppm})$, the proposed system exhibits a partial selectivity to other gases like $\mathrm{CO}, \mathrm{NO}_{2}, \mathrm{H}_{2} \mathrm{~S}$, and xylene. CNT tubes may also be used in piezoelectric based approaches as a sensor layer. For example, piezoelectric cantilevers coated with carbon nanotubes was able to monitor benzene (85), CO, and $\mathrm{NO}_{2}$ (86) presence in the air.

Good sensitivity and selectivity has made electrochemical biosensors to be one of the most common forms of gas detectors. A $\mathrm{sno}_{2}$-based gas sensor fabricated with radio-frequency induction plasma deposition (IPD) was also found to be very sensitive to indoor air pollutants $\left(\mathrm{HCHO}\right.$ and $\left.\mathrm{NO}_{2}\right)$ at a concentration of $20 \mathrm{ppb}$ with rapid response and recovery time (87). The sensing films consist of nano-sized particles, and when combined with nickel oxide $\left(\mathrm{SnO}_{2}-\mathrm{NiO}\right)$, the polycrystalline composite on a micro-hotplate sensor can detect formaldehyde at concentrations of $0.06 \mathrm{ppm}$, which is the indoor exposure limit in accordance with the Chinese Environmental Protection Agency (88). Nanosized $\mathrm{V}_{2} \mathrm{Ti}_{4} \mathrm{O}_{13}$ can also detect formaldehyde in the range $0.1-40 \mathrm{mg} / \mathrm{m}^{3}$ with a detection limit of $0.06 \mathrm{mg} / \mathrm{m}^{3}$ using cataluminescence (89). It has also demonstrated good stability for continuous monitoring of formaldehyde over 80 hours without interference from other gases passing through the sensor. Measurement of resistance changes of a nickel oxide $(\mathrm{NiO})$ layer and a platinum interdigitated electrode (IDE) is another way to detect formaldehyde (90). An adsorption/combustion-type gas sensor using $\mathrm{Pd} / \gamma-\mathrm{Al}_{2} \mathrm{O}_{3}$ as a sensing material and $\gamma-\mathrm{Al}_{2} \mathrm{O}_{3}$ as a compensating material was fabricated by the micro-electro-mechanical system (MEMS) technology on a silicon substrate (91). Experimental results have shown that this system can detect very low concentrations of toluene (10 ppb) within a short data acquisition time (measurable every 20 seconds), and results are independent of temperature and humidity. In another electrochemical approach, solid-state sensors may be used for developing reliable, sensitive, cost-effective, portable and simple to operate air toxicity sensors (92). However, the major focus of research in this field is concentrating on screen printing technologies, which underpins the progressive drive towards real miniature, portable and commercially available devices. Similar to the air sensors discussed, screen printed electrodes may be modified with different polymers, which is supposed to change its conductivity upon interaction with the analyte. Using this approach, screen printed electrodes were modified with hydrazinium polyacrylate for formaldehyde detection (93), polytetrafluoroethylene for measuring multiple gases including oxygen, methane, ozone and sulfur dioxide (94) and solid polymer electrolytes for NOx sensor fabrication (95). There are many other electrochemical sensors in development today, and we have only mentioned the tip of the iceberg.

Optical gas sensors provides a good alternative to the piezoelectric and conductometric gas sensors. Chemiluminescence on a solid material was discovered a long time ago and can be applicable for gas sensing via an optical transducer. An example is yttrium oxide $\left(\mathrm{Y}_{2} \mathrm{O}_{3}\right)$ powder, a sensitive chemiluminescence material that can detect and quantify benzene vapor at the linear range $4-7018 \mathrm{mg} / \mathrm{m}^{3}(\mathrm{r}=0.9981, \mathrm{n}=11)$ and detection limit of $1 \mathrm{mg} / \mathrm{m}^{3}$ for more than $80 \mathrm{~h}$ (96). In one of the optical approaches, a colorimetric sensor made from porous glass impregnated with Schiff's reagent and acid for detecting formaldehyde presence in the air was used. There was a colour change from yellow to violet, when exposed to formaldehyde, allowing the development of a sensor with a detection a limit between $20 \mathrm{ppm}$ to $10 \mathrm{ppb}$ (97). The non-dispersive infrared (NDIR) $\mathrm{CO}_{2}$ gas sensor with optical cavities and two elliptical mirrors optimized for the optical path and light intensity is an example of an optical-based sensor (98). It has two distinct features: one is focusing infrared (IR) light onto the detector with a minimum cavity volume and the other is an increased optical path length to enhance the sensitivity and accuracy. Other optical approaches are based on changes in the sensing membranes reflective indeces, induced by the presence of the toxicants in the air. These sensing materials may be used as dyes (99), crystals (100) or as a thin film placed on the prisms (101) or fiber optics. Fiber optic gas sensors are usually based on the fiber from which clad is removed, and core modified with sensing membranes, such as zinc vanadate (102) or Ho-doped bismuth oxide (103) for ammonia, ethanol, methanol and acetone gases detection, Nile red with polyvinylpyrrolidone for VOCs (104) and nano-crystalline zinc oxide for acetone, isopropyl alcohol and benzene gases detection (105).

Biosensors allow the detection of biochemical agents using biological elements such as microorganisms, enzymes, antibodies, nucleic acids, tissues, and cell receptors. There are three main parts to a biosensor. First is the bio-recognition component, and then the interface which offers the immobilization of the bioreceptor, to the last part, which is a transducer. For real-time air pollution monitoring, bioluminescent assays have gained increased attention due to the advancements in genetic manipulation that offers the possibility of changing a non-emitting microorganism into one that is luminescent in the presence of a specific analyte (106). Genetic engineering also enables programming of bacteria to respond in a desired way to a certain class of compounds. When bacteria are used (whole cell sensors), they can detect the presence of pollutants and provide information about the associated biological effects triggered by the pollutant (107). Information on the toxicity effects of chemical compounds may be more important and valuable than the determination of the exact chemical composition of the indoor air.

One example of a whole cell biosensors is the use of a Pseudomonas strain as a recognition element in a biosensor system within a flow-through cell measuring sample injector to detect low concentrations of naphthalene (108). The lower limit of naphthalene detection by HK44 is of $0.02 \mathrm{mg} / \mathrm{L}(0.16 \mu \mathrm{m})$, is below the health advisory limit as suggested by EPA. The same bacterial strain, when immobilized on $2 \%$ agar gel, was used 


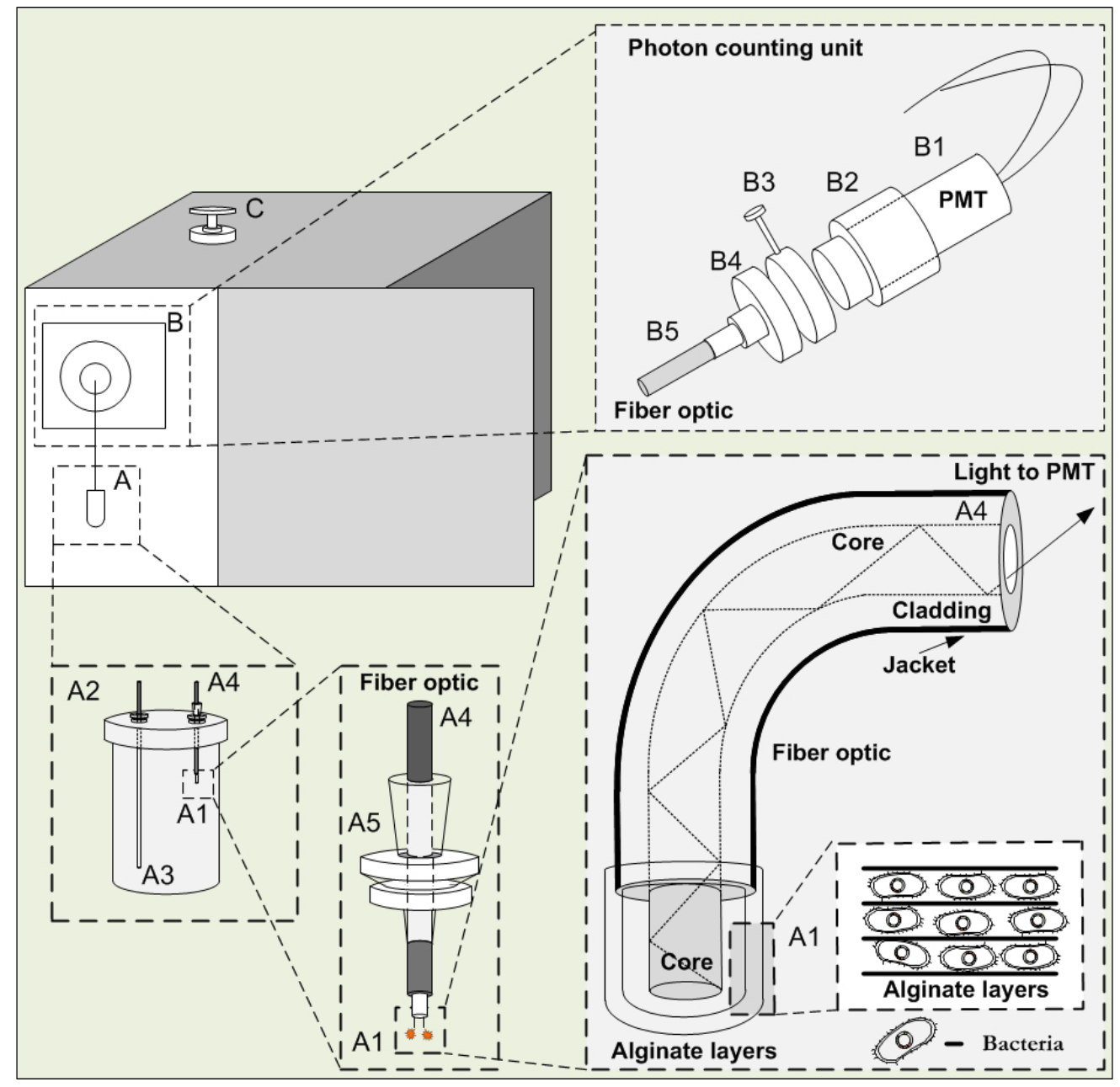

Figure 3. Descriptive scheme of the fiber optic based setup for real time monitoring of toxicity in the air. A, detection unit; $A 1$, hermetic chamber; $A 2$, alginate matrix with bacteria immobilized on the fiber optic core; $A 3$, needle for air pollutant entrance; 4 4, fiber optic; A5, fiber optic holder; B, photon counting unit; B1, Hamamatsu HC135-01 PMT Sensor Module; B2, PMT fixation ring; B3, manual shutter (71430, Oriel); B4, fiber holder that prevents the movement of the fiber inside the photon counting unit; B5, fiber optic; C, outside handle of manual shutter that enables light access to the PMT (1).

with a dynamic atmosphere generator and naphthalene emission source (109). The good linear response was obtained between 50 and $260 \mathrm{nmol} / \mathrm{L}$ with a detection limit estimated at $20 \mathrm{nmol} / \mathrm{L}$ which is far below the recommended threshold value. In another example, a reconstructed bioluminescent pseudomonas putida naphthalene biosensor using a NAH7 plasmid and a chromosomally inserted gene fusion between the sal promoter and $l u x A B$ genes was used to perform a filter-immobilized biosensor in a closed flask, with a naphthalene-contaminated aqueous phase (110). Bioluminescence of the cells was proportional to the naphthalene concentration. This is probably due to the faster rate of transport in the gaseous phase, which resulted in bacteria showing a 10-fold lower detection limit in aqueous compared to the gaseous phase. Therefore, bio-reporter bacteria have shown good sensitivity for air pollution measurements.

In our laboratory, two bioluminescence bacterial reporter strains (genotoxicity and cytotoxicity sensitive) were used to monitor air pollution (111). Various bacteria were immobilized in different matrices and exposed to the air pollutants in differ- ent volumes and matrices. The TV1061 strain immobilized in alginate showed the best sensitivity to some tested compounds. A direct connection was found between the volume of the immobilization bed and corresponding response of the bacteria and viability. Consequently, a novel online fiber optic-based biosensor was produced (Fig. 3). A TV1061 strain was immobilized with alginate on the proximal end of a fiber optic and exposed to different air pollutants. Three layers of alginate were optimal for air monitoring, and our sensor demonstrated that different pollutants have different bioluminescence kinetic responses. For all pollutants, ppb level of sensitivity was achieved using our bioluminescence bacteria reporter. In continuation of this work, bioreporter bacteria were immobilized in calcium alginate pads, integrated with CMOS sensors and measured in a real indoor environment (1). After different optimization steps (e.g., pad orientation, temperature, and time of exposure), the sensor was exposed to different chemicals and products available in the market that can usually be found in an indoor environment (e.g., cigarette smoke, acetone, paints, etc.). The proposed device is only the first step towards a user-friendly, 
portable and sensitive devices, which allows for real-time and continuous air monitoring in indoor environments. Non-modified bioluminescent microorganisms also may be used in air monitoring devices. An example are bacteria obtained from marine fish, immobilized in Ca-alginate beads and exposed to common air pollutants, i.e. $\mathrm{SO}_{2} \mathrm{H}_{2} \mathrm{~S}, \mathrm{CO}_{2}$ and $\mathrm{NH}_{3}$ (112). In this case, the presence of the air pollutant was indicated by bacterial light activity inhibition. Another approach used filamentous green alga Klebsormidium for the detection of methanol and formaldehyde in the vapor (113). The proposed sensor was operative for 30 days and showed good sensitivity (75 ppm) to the tested toxicants. The main conclusion from this study was that algal-based biosensors were suitable to detect VOCs in the air. For the simultaneous detection and identification of several targets by one biosensor, the same research group used three membrane-immobilized algal strains of genus Klebsormidium and Chlorella in one biosensor application to monitor different VOCs in the air(114). Using the IMAGING-PAM chlorophyll fluorimeter this sensor provides dose-dependent and reversible responses to formaldehyde and methanol in concentrations acceptable to human health from $10 \mathrm{ppb}$ to $10 \mathrm{ppm}$. Microbial fuel cell (MFC) sensors also demonstrated good potential in air toxicity monitoring. In this approach, the effect of the environment on the microbial activities may be monitored using different measurement technologies, i.e. electrochemical or optical. In electrochemical sensors, the bacterial culture's electrochemical properties are affected by chemicals in the air and are measured using integrated electrodes. For example, an MFC sensor based on biocathode sensing elements allows for the detection of 20-ppm formaldehyde (115) or carbon monoxide (116) in air.

Besides detecting the presence of air pollutants, some bacteria can degrade toxic compounds. Pseudomonas putida strains can aerobically degrade benzene $(0.02-0.14 \mathrm{mM}$, baseline recovery time of $15 \mathrm{~min})$, toluene $(0.05-0.2 \mathrm{mM}$, baseline recovery time of $20 \mathrm{~min}$ ) and ethylbenzene $(0.1-0.02 \mathrm{mM}$, baseline recovery time of $30 \mathrm{~min}$ ) (117). The difference in baseline recovery time for each type of analyte makes it possible to tell the compounds apart in mixtures of these VOCs. The reproducibility and simplicity of this biosensor makes it a reliable initial warning device for indoor air monitoring. Another whole cell application is the use of $E$-coli which contains the TOL plasmid (responsible for the degradation of benzene and its derivatives) fused with the genes of firefly luciferase (118). This application offers a rapid, inexpensive and sensitive technique for environmental detection of aromatic pollutant compounds. Diffusion of gases into the cells affect the sensitivity of the biosensors. The sensitivity can be improved by increasing the surface in contact with the chemicals and by reducing the volume of the immobilized cell layer. Biosensors also allows remote operations when immobilized bacteria are placed inside a specially constructed miniature flow cell which also houses the transducer, power source, and transmitter that converts the light signal into radio frequencies to be picked up at experimental headquarters (119).
Fungi (e.g., Alternaria alternata, Eurotium herbariorum, and Aspergillus penicillioides) have also been used as sensors for detecting formaldehyde in the air (120). Fungal mycelium length and optical transparency of the biosensor plate were employed as indices of the fungal growth, which are climate dependent (121).

Another class of biosensors is based on enzymes. Electrochemical biosensors binds enzymes to the electrode via immobilization technique to enable a high sensitivity and selectivity with short response time measurement. For example, formaldehyde emitted from timber materials was successfully measured by formaldehyde dehydrogenase (FALDH) immobilized on a Pt-electrode coated with hydrophilic PTFE, in the range from 40 to $2000-3000 \mathrm{ppb}$ (122). This detection range covers the detection limit of the human sense of smell (410 ppb) and this is an effective and convenient approach for measuring gaseous formaldehyde in an indoor environment. Utilizing different enzymes can create sensors sensitive to the wild group of indoor air pollutants. However, enzyme-based biosensors face the problem of the decreasing activity of the bioreporters during the immobilization step, and the long-term storage stability. Research is ongoing to increase the stability of immobilized enzymes, and one study has shown that when FALDH is immobilized in mesoporous silica, the storage stability is prolonged and stable for over 80 days (123). This result is useful for developing high-performance electrochemical biosensors. Another research group used alcohol oxidase from the yeast Hansenula polymorpha and horseradish peroxidase for development of low-cost biosensors for semi-quantitative detection of airborne formaldehyde in concentrations higher than the threshold levels (124). The measuring method is based on the colour change of a solution that contains a mixture of two enzymes and a chromogen, after the exposure to airborne formaldehyde. Rapid visual detection and no need for unnecessary complicated instrumentation provides an attractive tool for the detection formaldehyde at concentrations that are dangerous to human health. The presence of the formaldehyde in the air also may be detected under continuous flow conditions by an online system comprising of a wet scrubber for a continuous transfer of the pollutant to an aqueous solution, a micro-reactor containing immobilized formaldehyde dehydrogenase (FDH), and a conductometric transducer (125). With the long-term operative stability (more than three months), the proposed system allowed formaldehyde detection in the range 0.05-2 ppm with a sensitivity of 20_S/ppm.

Structure guided protein engineering is a powerful tool for creation of selective protein-based biosensors that exclusively and specifically detect benzene and its derivatives (126), that possess the ability to specifically discriminate between alkyl substituted benzene derivatives; such as toluene, $m$-xylene, and mesitylene. Another approach uses the correlation between radon and its stable decay daughter ${ }^{210} \mathrm{~Pb}$, in the creation of sensitive, label-free, fluorescent monitors, in their detection in air (127), via a specific lead-induced aptamer HTG conformational change and the organic dye malachite green (MG), as the 
fluorescent probe with limits of detection for lead and radon detection, $6.7 \mathrm{nmol} / \mathrm{L}$ and $2.06 \times 10^{3} \mathrm{~Bq} \cdot \mathrm{h} / \mathrm{m}^{3}$, respectively.

The changing source of pollutants due to the constant change in building material and consumer products created many of the chemicals found in the indoor environment and occupants. Therefore, monitoring the concentration and type of pollutant and removal of this toxicant in the air is of utmost importance. We believe that biosensors can fulfill the need to detect and provide clean indoor air in the future as they provide detailed toxicity information unlike most of the other techniques.

\section{Future trends}

The area of biosensors for potential indoor air monitoring has made huge progress in the past decade. Progress in genetic technologies will allow the creation of better whole cell organisms and improve the specificity and variability of enzymatic bioreporters. Currently, the main disadvantage of indoor pollution monitoring systems is their inability in multiple analyte detection, even though most health effects are caused by exposure to a group of pollutants. Thus, the future emphasis will likely be on the creation of multi-array sensors based on different bioreporters (e,g, enzymes or whole cell organisms) which allows the detection of hundreds of wholly separate compounds.

Developing environmentally friendly composites with low or no pollutant emission and buildings with automatic ventilation systems that can monitor indoor and outdoor air will solve the root of the problem for indoor air pollution. Such advancement will help create a constant optimal environment in the air that can in turn increase work productivity and reduce negative health impacts. Currently, the health effects of pollutants are still not well understood and documented; therefore, the creation of a library of standard exposure values of toxicants would be useful.

Green buildings are the future of construction in most developed countries. It uses materials and products that generally releases reduced amounts of chemicals and pollutants at levels that will not harm human health. Rating systems such as the Leadership in Energy and Environmental Design (LEED) was developed by the U.S. Green Building Council to ensure the sustainability of these buildings for human health and the environment. Researchers have found that children living in green buildings have less asthma attacks and currently, the World Green Building Council is doing research on how green buildings affect the health and productivity of their users.

\section{Acknowledgment}

This publication is supported by the Singapore National Research Foundation under CREATE programme "Nanomaterials for Energy and Water Management".

\section{Author contribution}

Authors contributed equally to the production of the manuscript.

\section{Conflict of interest statement}

The authors declare no financial or commercial conflict of interest.

\section{References}

1. Etzov E, Cohen A,Marks RS, Bioluminescent Liquid Light Guide Pad Biosensor for Indoor Air Toxicity Monitoring. Analytical Chemistry, 2015; 87(7): p. 3655-3661.

2. Antikainen R, Lappalainen S, Lonnqvist A, Maksi-Mainen K, Reijula K,Uusi-Rauva E, Exploring the relationship between indoor air and productivity. Scandinavian Journal of Work Environment \& Health, 2008: p. 79-82.

3. Wargocki P, Wyon DP, Baik YK, Clausen G,Fanger PO, Perceived air quality, Sick Building Syndrome (SBS) symptoms and productivity in an office with two different pollution loads. Indoor Air-International Journal of Indoor Air Quality and Climate, 1999; 9(3): p. 165-179.

4. Molhave L, Clausen G, Berglund B, de Ceaurriz J, Kettrup A, Lindvall T, Maroni M, Pickering AC, Risse U, Rothweiler $\mathrm{H}$, Seifert $B$,Younes $M$, Total volatile organic compounds (TVOC) in indoor air quality investigations. Indoor Air-International Journal of Indoor Air Quality and Climate, 1997; 7(4): p. 225-240.

5. Bari MA, Kindzierski WB, Wheeler AJ, Heroux ME,Wallace LA, Source apportionment of indoor and outdoor volatile organic compounds at homes in Edmonton, Canada. Building and Environment, 2015; 90: p. 114-124.

6. Bako-Biro Z, Wargocki P, Weschler CJ,Fanger PO, Effects of pollution from personal computers on perceived air quality, SBS symptoms and productivity in offices. Indoor Air, 2004; 14(3): p. 178187.

7. Lee SC, Chan LY,Chiu MY, Indoor and outdoor air quality investigation at 14 public places in Hong Kong. Environment International, 1999; 25(4): p. 443-450.

8. Hong $\mathrm{T}$, Kim J,Lee $\mathrm{M}$, Integrated task performance score for the building occupants based on the $\mathrm{CO} 2$ concentration and indoor climate factors changes. Applied Energy, 2018; 228: p. 1707-1713.

9. Hodgson AT, Beal D,Mcllvaine JER, Sources of formaldehyde, other aldehydes and terpenes in a new manufactured house. Indoor Air, 2002; 12(4): p. 235-242.

10. Kelly TJ, Smith DL,Satola J, Emission rates of formaldehyde from materials and consumer products found in California homes. Environmental Science \& Technology, 1999; 33(1): p. 81-88.

11. Kawamura K, Kerman K, Fujihara M, Nagatani N, Hashiba T,Tamiya $\mathrm{E}$, Development of a novel hand-held formaldehyde gas sensor for the rapid detection of sick building syndrome. Sensors and Actuators B-Chemical, 2005; 105(2): p. 495-501.

12. Dirksen JA, Duval K,Ring TA, NiO thin-film formaldehyde gas sensor. Sensors and Actuators B-Chemical, 2001; 80(2): p. 106-115.

13. Seiyama T, Kato A, Fujiishi K,Nagatani M, A New Detector for gaseous Components using Semiconductive Thin Films. Analytical Chemistry, 1962; 34(11): p. 1502-1503.

14. Weschler CJ, Shields HC,Nalk DV, Indoor Chemistry involving O3, NO, and NO2 as Evidenced by 14 Months of Measurements at a site in Southern California. Environmental Science \& Technology, 1994; 28(12): p. 2120-2132.

15. Petit PC, Fine DH, Vasquez GB, Gamero L, Slaughter MS,Dasse KA, The Pathophysiology of Nitrogen Dioxide During Inhaled Nitric Oxide Therapy. Asaio Journal, 2017; 63(1): p. 7-13.

16. Blomberg A, Krishna MT, Bocchino V, Biscione GL, Shute JK, Kelly FJ, Frew AJ, Holgate ST,Sandstrom T, The inflammatory effects of 2 ppm NO2 on the airways of healthy subjects. American Journal of Respiratory and Critical Care Medicine, 1997; 156(2): p. 418-424.

17. Hui PS, Wong LT, Mui KW,Law KY, Survey of unsatisfactory levels of airborne bacteria in air-conditioned offices. Indoor and Built Environment, 2007; 16(2): p. 130-138.

18. Peltola J, Andersson MA, Haahtela T, Mussalo-Rauhamaa H, Rainey FA, Kroppenstedt RM, Samson RA,Salkinoja-Salonen MS, Toxic-metabolite-producing bacteria and fungus in an indoor envi- 
ronment. Applied and Environmental Microbiology, 2001; 67(7): p. 3269-3274.

19. Salonen H, Lappalainen S, Lindroos O, Harju R,Reijula K, Fung and bacteria in mould-damaged and non-damaged office environments in a subarctic climate. Atmospheric Environment, 2007; 41(32): p. 6797-6807.

20. Gołofit-Szymczak M,Górny RL, Microbiological air quality in office buildings equipped with different ventilation systems. Indoor Air; $0(0)$.

21. Harrison J, Pickering CAC, Faragher EB, Austwick PKC, Little SA,Lawton L, An Investigation of the Relationship between Microbial and Particulate Indoor Air-Pollution and the Sick Building Syndrome. Respiratory Medicine, 1992; 86(3): p. 225-235.

22. Jaakkola JJK,Miettinen $P$, Type of Ventilation System in Office Buildings and Sick Building Syndrome. American Journal of Epidemiology, 1995; 141 (8): p. 755-765.

23. Mendell MJ, Fisk WJ, Deddens JA, Seavey WG, Smith AH, Smith DF, Hodgson AT, Daisey JM,Goldman LR, Elevated symptom prevalence associated with ventilation type in office buildings. Epidemiology, 1996; 7(6): p. 583-589.

24. Becher R, Øvrevik J, Schwarze EP, Nilsen S, Hongslo KJ,Bakke VJ, Do Carpets Impair Indoor Air Quality and Cause Adverse Health Outcomes: A Review. International Journal of Environmental Research and Public Health, 2018; 15(2).

25. Zuskin E, Schachter E, Mustajbegovic J, Pucarin-Cvetkovic J, Doko-Jelinic J,Mucic-Pucic B, Indoor air pollution and effects on human health. Periodicum Biologorum, 2009; 111(1): p. 37-40.

26. Bernstein JA, Alexis N, Bacchus H, Bernstein IL, Fritz P, Horner E, Li N, Mason S, Nel A, Oullette J, Reijula K, Reponen T, Seltzer J, Smith A,Tarlo SM, The health effects of nonindustrial indoor air pollution. Journal of Allergy and Clinical Immunology, 2008; 121(3): p. 585-591.

27. Hardin BD, Kelmen BJ,Saxon A, Adverse human health effects associated with molds in the indoor environment. Journal of Occupational and Environmental Medicine, 2003; 45(5): p. 470-478.

28. Hizrri A, Zati Nabilah MG, Nurul Amni Z, Shahida N, Maryam Z, Hazrin AH, Mohd Faez S,Mohd Shukri MA, Indoor air quality (IAQ) characteristics and its microbial community identifications at two selected schools in Pahang, Malaysia: a preliminary study. Asian Journal of Agriculture and Biology, 2018(No.Special Issue): p. 8896.

29. Yu BF, Hu ZB, Liu M, Yang HL, Kong QX,Liu YH, Review of research on air-conditioning systems and indoor air quality control for human health. International Journal of Refrigeration, 2009; 32(1): p. 3-20.

30. Kim H,Bernstein JA, Air pollution and allergic disease. Current Allergy and Asthma Reports, 2009; 9(2): p. 128-133.

31. Maroni M, Seifert B,Lindvall T, eds. Indoor Air Quality - A Comprehensive Reference Book. 1995, Amsterdam-Lausanne-New York-Oxford-Shannon-Tokyo: Elsevier.

32. Ruano-Ravina A,Miguel Barros-Dios J, Randon and lung cancer. Implications for health workers, citizens and public administrations. Medicina Clinica, 2007; 128(14): p. 545-549.

33. Lee YCA, Cohet C, Yang YC, Stayner L, Hashibe M,Straif K, Meta-analysis of epidemiologic studies on cigarette smoking and liver cancer. International Journal of Epidemiology, 2009; 38(6): p. 1497-1511.

34. Jones AP, Indoor air quality and health. Atmospheric Environment, 1999; 33(28): p. 4535-4564.

35. Kim S-H, Hwang WJ, Cho J-S,Kang DR, Attributable risk of lung cancer deaths due to indoor radon exposure. Annals of Occupational and Environmental Medicine, 2016; 28(1): p. 8.

36. Lyman GH, Radon, in Indoor Air Pollution and Health, E.J. Bardana and A. Montanaro, Editors. 1997, Marcel Dekker: New York. p. 83103.
37. Nielson KK, Rogers VC, Holt RB, Pugh TD, Grondzik WA,deMeijer RJ, Radon penetration of concrete slab cracks, joints, pipe penetrations, and sealants. Health Physics, 1997; 73(4): p. 668-678.

38. Cohen BS, Xiong JQ, Fang CP,Li W, Deposition of charged particles on lung airways. Health Physics, 1998; 74(5): p. 554-560.

39. Klemm R, Mason RJ, Heilig C, Neas L,Dockery D, Is daily mortality associated specifically with fine particles? Data reconstruction and replication of analyses. Journal of Air Waste Management Association, 2000; 50(7): p. 1215-22.

40. Ostro B, Broadwin R, Green S, Feng WY,Lipsett M, Fine particulate air pollution and mortality in nine California counties: Results from CALFINE. Environmental Health Perspectives, 2006; 114(1): p. 29-33.

41. Rashed MN, Total and Extractable Heavy Metals in Indoor, Outdoor and Street Dust from Aswan City, Egypt. Clean-Soil Air Water, 2008; 36(10-11): p. 850-857.

42. Kumar R, Nagar JK,Gaur SN, Indoor Air Pollutants and Respiratory Morbidity - A Review. Indian Journal of Allergy Asthma and Immunology, 2005; 19(1): p. 1-9.

43. Covaci A, Voorspoels S, de Boer J, Determination of brominated flame retardants, with emphasis on polybrominated diphenyl ethers (PBDEs) in environmental and human samples - a review. Environment International, 2003; 29(6): p. 735-756.

44. Kharlyngdoh JB, Pradhan A, Asnake S, Walstad A, Ivarsson P,Olsson $\mathrm{P}-\mathrm{E}$, Identification of a group of brominated flame retardants as novel androgen receptor antagonists and potential neuronal and endocrine disrupters. Environment International, 2015; 74: $\mathrm{p}$. 60-70.

45. Costa LG, de Laat R, Tagliaferri S,Pellacani C, A mechanistic view of polybrominated diphenyl ether (PBDE) developmental neurotoxicity. Toxicology Letters, 2014; 230(2): p. 282-294.

46. Jin X, Lee S, Jeong Y, Yu J-P, Baek WK, Shin K-H, Kannan K,Moon $H-B$, Species-specific accumulation of polybrominated diphenyl ethers (PBDEs) and other emerging flame retardants in several species of birds from Korea. Environmental Pollution, 2016; 219: p. 191-200.

47. Lee $\mathrm{Y}-\mathrm{H}, \mathrm{Kim} \mathrm{H}-\mathrm{H}$, Lee J-I, Lee J-H, Kang H,Lee J-Y, Indoor contamination from pesticides used for outdoor insect control. Science of the Total Environment, 2018; 625: p. 994-1002.

48. Chen YL,Wen J, Sensor system design for building indoor air protection. Building and Environment, 2008; 43(7): p. 1278-1285.

49. Liu $X$,Zhai $Z$, Protecting a whole building from critical indoor contamination with optimal sensor network design and source identification methods. Building and Environment, 2009; 44(11): p. 2276-2283.

50. Methods for Monitoring Indoor Air Quality in Schools. 2011, World Health Organization Regional Office for Europe, JRC European Commission

51. Weschler CJ,Shields HC, Potential reactions among indoor pollutants. Atmospheric Environment, 1997; 31(21): p. 3487-3495.

52. Wang DKW,Austin CC, Determination of complex mixtures of volatile organic compounds in ambient air: canister methodology. Analytical and Bioanalytical Chemistry, 2006; 386(4): p. 10991120.

53. Mui KW, Wong LT,Ho WL, Evaluation on sampling point densities for assessing indoor air quality. Building and Environment, 2006; 41(11): p. 1515-1521.

54. Praveen K. S, Eric L. B, Rangachary M,Fernando H. G, Chemical Sensors for Environmental Monitoring and Homeland Security. The Electrochemical Society Interface, 2010: p. 35-40.

55. Persaud K,Dodd G, Analysis of Discrimination Mechanisms in the Mammalian Olfactory System using a Model Nose. Nature, 1982; 299(5881): p. 352-355.

56. Dusastre V, Electronic noses: Principles and applications. Nature, 1999; 402(6760): p. 351-352. 
57. Fang X, Qi G, Guo M, Pan M, Chen YQ,leee, An improved integrated electronic nose for online measurement of VOCs in indoor air, in 2005 27th Annual International Conference of the IEEE Engineering in Medicine and Biology Society, Vols 1-7. 2005. p. 2894-2897.

58. Zampolli S, Elmi I, Ahmed F, Passini M, Cardinali GC, Nicoletti S,Dori L, An electronic nose based on solid state sensor arrays for low-cost indoor air quality monitoring applications. Sensors and Actuators B-Chemical, 2004; 101(1-2): p. 39-46.

59. Xu K, Fu C, Gao Z, Wei F, Ying Y, Xu C,Fu G, Nanomaterial-based gas sensors: A review. Instrumentation Science \& Technology, 2018; 46(2): p. 115-145.

60. Mohan VB, Lau KT, Hui D,Bhattacharyya D, Graphene-based materials and their composites: A review on production, applications and product limitations. Composites Part B-Engineering, 2018; 142: p. 200-220.

61. Schedin F, Geim AK, Morozov SV, Hill EW, Blake P, Katsnelson $\mathrm{MI}$, Novoselov KS, Detection of individual gas molecules adsorbed on graphene. Nature Materials, 2007; 6(9): p. 652-655.

62. Cretu V, Postica V, Mishra AK, Hoppe M, Tiginyanu I, Mishra YK, Chow L, de Leeuw NH, Adelung R,Lupan O, Synthesis, characterization and DFT studies of zinc-doped copper oxide nanocrystals for gas sensing applications. Journal of Materials Chemistry A, 2016; 4(17): p. 6527-6539.

63. Li TM, Zeng W, Long HW,Wang ZC, Nanosheet-assembled hierarchical $\mathrm{SnO} 2$ nanostructures for efficient gas-sensing applications. Sensors and Actuators B-Chemical, 2016; 231: p. 120-128.

64. Gonzalez O, Roso S, Vilanova X,Llobet E, Enhanced detection of nitrogen dioxide via combined heating and pulsed UV operation of indium oxide nano-octahedra. Beilstein Journal of Nanotechnology, 2016; 7: p. 1507-1518.

65. Yoo R, Kim J, Song MJ, Lee W,Noh JS, Nano-composite sensors composed of single-walled carbon nanotubes and polyaniline for the detection of a nerve agent simulant gas. Sensors and Actuators B-Chemical, 2015; 209: p. 444-448.

66. Yoosefian $M$, Powerful greenhouse gas nitrous oxide adsorption onto intrinsic and Pd doped Single walled carbon nanotube. Applied Surface Science, 2017; 392: p. 225-230.

67. Dong CK, Luo HJ, Cai JQ, Wang FQ, Zhao YY,Li DT, Hydrogen sensing characteristics from carbon nanotube field emissions. Nanoscale, 2016; 8(10): p. 5599-5604.

68. Xiao ZH, Kong LB, Ruan SC, Li XL, Yu SJ, Li XY, Jiang Y, Yao ZJ, Ye S, Wang $\mathrm{CH}$, Zhang TS, Zhou K,Li S, Recent development in nanocarbon materials for gas sensor applications. Sensors and Actuators B-Chemical, 2018; 274: p. 235-267.

69. Wei BY, Hsu MC, Su PG, Lin HM, Wu RJ,Lai HJ, A novel SnO2 gas sensor doped with carbon nanotubes operating at room temperature. Sensors and Actuators B-Chemical, 2004; 101(1-2): p. 81-89.

70. Wang J, Liu L, Cong S-Y, Qi J-Q,Xu B-K, An enrichment method to detect low concentration formaldehyde. Sensors and Actuators B-Chemical, 2008; 134(2): p. 1010-1015.

71. Bittencourt C, Felten A, Espinosa EH, lonescu R, Llobet E, Corteig $\mathrm{X}$,Pireaux JJ, WO3 films modified with functionalised multi-wall carbon nanotubes: Morphological, compositional and gas response studies. Sensors and Actuators B-Chemical, 2006; 115(1): p. 33-41.

72. Li Y, Wang $\mathrm{H}-\mathrm{c}$, Yang $\mathrm{M}-\mathrm{j}, \mathrm{n}$-Type gas sensing characteristics of chemically modified multi-walled carbon nanotubes and PMMA composite. Sensors and Actuators B-Chemical, 2007; 121(2): p. 496-500.

73. Liu YL, Yang HF, Yang Y, Liu ZM, Shen GL, Yu RQ, Gas sensing properties of tin dioxide coated onto multi-walled carbon nanotubes. Thin Solid Films, 2006; 497(1-2): p. 355-360.

74. Penza M, Rossi R, Alvisi M, Cassano G, Signore MA, Serra E,Giorgi R, Pt- and Pd-nanoclusters functionalized carbon nanotubes networked films for sub-ppm gas sensors. Sensors and Actuators
B-Chemical, 2008; 135(1): p. 289-297.

75. Arnold C, Harms M,Goschnick J, Air Quality Monitoring and Fire Detection With The Karlsruhe Electronic Micronose KAMINA. leee Sensors Journal, 2002; 2(3): p. 179-188.

76. Yang $L$, Yin $C B$, Zhang $Z L$, Zhou JJ,Xu HH, The investigation of hydrogen gas sensing properties of SAW gas sensor based on palladium surface modified $\mathrm{SnO} 2$ thin film. Materials Science in Semiconductor Processing, 2017; 60: p. 16-28.

77. Singh H, Raj VB, Kumar J, Durani F, Mishra M, Nimal AT,Sharma MU, SAW mono sensor for identification of harmful vapors using PCA and ANN. Process Safety and Environmental Protection, 2016; 102: p. 577-588.

78. Rana L, Gupta R, Tomar M,Gupta V, ZnO/ST-Quartz SAW resonator: An efficient NO2 gas sensor. Sensors and Actuators B-Chemical, 2017; 252: p. 840-845.

79. Staline J,Dr TS, Design and Analysis of SAW Based MEMS Gas Sensor for the Detection of Volatile Organic Gases. International Journal of Engineering Research and Applications, 2014; 4(3): p. 254-258.

80. Wang W, Hu HL, Liu XL, He ST, Pan Y, Zhang CH,Dong C, Development of a Room Temperature SAW Methane Gas Sensor Incorporating a Supramolecular Cryptophane A Coating. Sensors, 2016; 16(1).

81. Thomas S, Cole M, Villa-López FH,Gardner JW, High frequency surface acoustic wave resonator-based sensor for particulate matter detection. Sensors and Actuators A: Physical, 2016; 244: p. 138145.

82. Zhou J, Li P, Zhang S, Long YC, Zhou F, Huang YP, Yang PY,Bao MH, Zeolite-modified microcantilever gas sensor for indoor air quality control. Sensors and Actuators B-Chemical, 2003; 94(3): p. 337342.

83. Bearzotti A, Macagnano A, Papa P, Venditti I,Zampetti E, A study of a QCM sensor based on pentacene for the detection of BTX vapors in air. Sensors and Actuators B: Chemical, 2017; 240: p. 11601164.

84. Kumar A, Brunet J, Varenne C, Ndiaye A, Pauly A, Penza M,Alvisi $M$, Tetra-tert-butyl copper phthalocyanine-based QCM sensor for toluene detection in air at room temperature. Sensors and Actuators B: Chemical, 2015; 210: p. 398-407.

85. Clément $\mathrm{P}$, Llobet $\mathrm{E}$, Lucat $\mathrm{C}$,Debéda $\mathrm{H}$, Use of a CNT-coated Piezoelectric Cantilever with Double Transduction As a Gas Sensor for Benzene Detection at Room Temperature. Procedia Engineering, 2014; 87: p. 708-711.

86. Clément $P$, Llobet $E$, Lucat $C$,Debéda $H$, Gas Discrimination Using Screen-printed Piezoelectric Cantilevers Coated with Carbon Nanotubes. Procedia Engineering, 2015; 120: p. 987-992.

87. Shi LQ, Hasegawa Y, Katsube T, Nakano M, Nakamura K,leee, Highly sensitive $\mathrm{SnO} 2$-based gas sensor for indoor air quality monitoring. Transducers '05, Digest of Technical Papers, Vols 1 and 2. 2005. 1203-1206.

88. Lv P, Tang ZA, Yu J, Zhang FT, Wei GF, Huang ZX,Hu Y, Study on a micro-gas sensor with $\mathrm{SnO} 2-\mathrm{NiO}$ sensitive film for indoor formaldehyde detection. Sensors and Actuators B-Chemical, 2008; 132(1): p. 74-80.

89. Zhou K, Ji X, Zhang N,Zhang X, On-line monitoring of formaldehyde in air by cataluminescence-based gas sensor. Sensors and Actuators B-Chemical, 2006; 119(2): p. 392-397.

90. Lee $\mathrm{C}-\mathrm{Y}$, Chiang $\mathrm{C}-\mathrm{M}$, Wang $\mathrm{Y}-\mathrm{H}, \mathrm{Ma} \mathrm{R}-\mathrm{H}$, A self-heating gas sensor with integrated $\mathrm{NiO}$ thin-film for formaldehyde detection. Sensors and Actuators B-Chemical, 2007; 122(2): p. 503-510.

91. Sasahara T, Kato H, Saito A, Nishimura M,Egashira M, Development of a ppb-level sensor based on catalytic combustion for total volatile organic compounds in indoor air. Sensors and Actuators B-Chemical, 2007; 126(2): p. 536-543.

92. Schwandt C, Kumar RV,Hills MP, Solid state electrochemical gas 
sensor for the quantitative determination of carbon dioxide. Sensors and Actuators B: Chemical, 2018; 265: p. 27-34.

93. Menart E, Jovanovski $\mathrm{V}$,Hočevar SB, Novel hydrazinium polyacrylate-based electrochemical gas sensor for formaldehyde. Sensors and Actuators B: Chemical, 2017; 238: p. 71-75.

94. Wan $\mathrm{H}$, Yin $\mathrm{H}$, Lin L, Zeng X,Mason AJ, Miniaturized planar room temperature ionic liquid electrochemical gas sensor for rapid multiple gas pollutants monitoring. Sensors and Actuators B: Chemical, 2018; 255: p. 638-646.

95. Kuberský P, Syrový T, Hamáček A, Nešpůrek S,Syrová L, Towards a fully printed electrochemical NO2 sensor on a flexible substrate using ionic liquid based polymer electrolyte. Sensors and Actuators B: Chemical, 2015; 209: p. 1084-1090.

96. Rao Z, Liu L, Xie J,Zeng Y, Development of a benzene vapour sensor utilizing chemiluminescence on Y2O3. Luminescence, 2008; 23(3): p. 163-168.

97. Maruo YY, Nakamura J, Uchiyama M, Higuchi M, Izunli K, Development of formaldehyde sensing element using porous glass impregnated with Schiff's reagent. Sensors and Actuators B-Chemical, 2008; 129(2): p. 544-550.

98. Yi SH, Park YH, Han SO, Min NK, Kim ES, Ahn TH,leee, Novel NDIR $\mathrm{CO} 2$ sensor for indoor air quality monitoring. Transducers ' $05, \mathrm{Di}-$ gest of Technical Papers, Vols 1 and 2. 2005. 1211-1214.

99. Tavoli F,Alizadeh N, Optical ammonia gas sensor based on nanostructure dye-doped polypyrrole. Sensors and Actuators B-Chemical, 2013; 176: p. 761-767.

100. Burratti L, De Matteis F, Casalboni M, Francini R, Pizzoferrato R,Prosposito $P$, Polystyrene photonic crystals as optical sensors for volatile organic compounds. Materials Chemistry and Physics, 2018; 212: p. 274-281.

101. Paliwal A, Sharma A, Tomar M,Gupta V, Carbon monoxide (CO) optical gas sensor based on $\mathrm{ZnO}$ thin films. Sensors and Actuators B: Chemical, 2017; 250: p. 679-685.

102. Subramanian M, Dhayabaran VV, Sastikumar D,Shanmugavadivel $M$, Development of room temperature fiber optic gas sensor using clad modified Zn3 (VO4)2. Journal of Alloys and Compounds, 2018; 750: p. 153-163.

103. Manjula M, Karthikeyan B,Sastikumar D, Sensing characteristics of clad-modified (Ho-doped $\mathrm{Bi} 2 \mathrm{O} 3$ nanoparticles) fibre optic gas sensor. Optical Fiber Technology, 2018; 45: p. 35-39.

104. Khan MRR, Kang B-H, Yeom S-H, Kwon D-H,Kang S-W, Fiber-optic pulse width modulation sensor for low concentration VOC gas. Sensors and Actuators B: Chemical, 2013; 188: p. 689-696.

105. Renganathan $B, G a n e s a n A R$, Fiber optic gas sensor with nanocrystalline ZnO. Optical Fiber Technology, 2014; 20(1): p. 48-52.

106. Girotti S, Ferri EN, Fumo MG,Maiolini E, Monitoring of environmental pollutants by bioluminescent bacteria. Analytica Chimica Acta, 2008; 608(1): p. 2-29.

107. Roda A, Pasini P, Mirasoli M, Michelini E,Guardigli M, Biotechnological applications of bioluminescence and chemiluminescence. Trends in Biotechnology, 2004; 22(6): p. 295-303.

108. Valdman E, Valdman B, Battaglini F,Leite SGF, On-line detection of low naphthalene concentrations with a bioluminescent sensor. Process Biochemistry, 2004; 39(10): p. 1217-1222.

109. Valdman E,Gutz IGR, Bioluminescent sensor for naphthalene in air: Cell immobilization and evaluation with a dynamic standard atmosphere generator. Sensors and Actuators B-Chemical, 2008; 133(2): p. 656-663.

110. Werlen C, Jaspers MCM,van der Meer JR, Measurement of biologically available naphthalene in gas and aqueous phases by use of a Pseudomonas putida biosensor. Applied and Environmental Microbiology, 2004; 70(1): p. 43-51.
111. Eltzov E, Pavluchkov V, Burstain M,Marks R, Creation of a fiber optic based biosensor for air toxicity monitoring. Sensors \& Actuators: B. Chemical, 2011; in print (SNB12864).

112. Shakeel S, A., F.,Shraddha P, Bioluminescent bacteria: The sparkling hope for pollution detection. Indian Journal of Scientific Research, 2018; 8(1): p. 125-130.

113. Podola B,Melkonian $M, A$ long-term operating algal biosensor for the rapid detection of volatile toxic compounds. Journal of Applied Phycology, 2003; 15(5): p. 415-424.

114. Podola B, Nowack ECM,Melkonian M, The use of multiple-strain algal sensor chips for the detection and identification of volatile organic compounds. Biosensors and Bioelectronics, 2004; 19(10): p. $1253-1260$.

115. Jiang $Y$, Liang $P$, Huang $X$, Ren $Z J$, A novel microbial fuel cell sensor with a gas diffusion biocathode sensing element for water and air quality monitoring. Chemosphere, 2018; 203: p. 21-25.

116. Zhou S, Huang S, Li Y, Zhao N, Li H, Angelidaki I,Zhang Y, Microbial fuel cell-based biosensor for toxic carbon monoxide monitoring. Talanta, 2018; 186: p. 368-371.

117. Rasinger JD, Marrazza G, Briganti F, Scozzafava A, Mascini M,Turner APF, Evaluation of an FIA operated amperometric bacterial biosensor, based on pseudomonas putida F1 for the detection of benzene, toluene, ethylbenzene, and xylenes (BTEX). Analytical Letters, 2005; 38(10): p. 1531-1547.

118. Berno E, Marcondes DFP, Gamalero SR,Eandi M, Recombinant Escherichia coli for the biomonitoring of benzene and its derivatives in the air. Ecotoxicology and Environmental Safety, 2004; 57(2): p. 118-122.

119. Knopf GK, Bassi AS, Singh S,Macleod R, Biosensor for remote monitoring of airborne toxins, in Environmental Monitoring and Remediation Technologies Ii, T. VoDinh and R.L. Spellicy, Editors. 1999. p. 185-193.

120. Seo J, Kato S, Tatsuma T, Chino S, Takada K,Notsu H, Biosensing of an indoor volatile organic compound on the basis of fungal growth Chemosphere, 2008; 72(9): p. 1286-1291

121. Keiko A, A Method For Numerical Characterization Of Indoor Climates By A Biosensor Using A Xerophilic Fungus. Indoor Air, 1993; 3(4): p. 344-348.

122. Mitsubayashi K, Nishio G, Sawai M, Kazawa E, Yoshida H, Saito T, Kudo H, Otsuka K, Takao M,Saito H, A biochemical sniffer-chip for convenient analysis of gaseous formaldehyde from timber materials. Microchimica Acta, 2008; 160(4): p. 427-433.

123. Shimomura $T$, Itoh $T$, Sumiya $T$, Mizukami F,Ono M, Electrochemical biosensor for the detection of formaldehyde based on enzyme immobilization in mesoporous silica materials. Sensors and Actuators B-Chemical, 2008; 135(1): p. 268-275.

124. Sigawi S, Smutok O, Demkiv O, Gayda G, Vus B, Nitzan Y, Gonchar $M, N i s n e v i t c h$ M, Detection of Waterborne and Airborne Formaldehyde: From Amperometric Chemosensing to a Visual Biosensor Based on Alcohol Oxidase. Materials, 2014; 7(2): p. 1055.

125. Vianello F, Boscolo-Chio R, Signorini S,Rigo A, On-line detection of atmospheric formaldehyde by a conductometric biosensor. Biosensors and Bioelectronics, 2007; 22(6): p. 920-925.

126. Ray S, Panjikar S,Anand R, Design of Protein-Based Biosensors for Selective Detection of Benzene Groups of Pollutants. ACS Sensors, 2018; 3(9): p. 1632-1638.

127. Li S, Liu H, Yang G, Liu S, Liu R,Lv C, Detection of radon with biosensors based on the lead(II)-induced conformational change of aptamer HTG and malachite green fluorescence probe. Journal of Environmental Radioactivity, 2018; 195: p. 60-66. 